\title{
Successful en bloc resection of an esophageal hemangioma by endoscopic submucosal dissection
}

Esophageal hemangiomas are uncommon benign tumors [1]. Esophagectomy is the conventional surgical approach to treatment, but recently less invasive approaches by endoscopic therapy have become more widely used [2,3]. However, because conventional endoscopic therapy cannot obtain specimens for pathological examination and is associated with a risk of residual or recurrent hemangioma [4], en bloc removal is another possible treatment option. We report here the first case of a submucosal esophageal hemangioma successfully removed en bloc by endoscopic submucosal dissection (ESD).

A 41-year-old woman presented with dysphagia. Upper gastrointestinal endoscopy revealed a $25-\mathrm{mm}$ diameter, bluish submucosal mass in the upper esophagus (৫ Fig. 1).

Endoscopic ultrasound (EUS) showed a hypoechoic mass localized to the submucosa ( Fig. 2) [5] and computed tomography (CT) revealed a hyperdense mass that was not invading the surrounding organs. The mass was diagnosed as a submucosal hemangioma of the esophagus.

After informed consent had been obtained, ESD was performed under general anesthesia. Following an incision of the mucosal layer in the side of the stomach made using an improved insulated-tip (IT-2) knife (KD-611L; Olympus, Tokyo, Japan), the submucosal layer was dissected from the oral side using a needle knife (Dual knife, KD-650Q; Olympus). Although a submucosal vascular plexus was found, loose connective tissue was present in the submucosa directly above the muscular coat, which enabled dissection of the target layer. There were several large blood vessels running from the muscular coat but hemostasis was secured with coagulation forceps (Coagrasper, FD411QR; Olympus), which blocked the flow from these vessels ( $\bullet$ Fig. 3 ).

As a result of having a clear operative field for ESD, the dissection could be performed leaving the hypervascular hemangioma undisturbed ( $\bullet$ Fig. 4).

The resected specimen contained a dark purple mass ( $\bullet$ Fig. 5).

Histopathological results revealed outgrowths of dilated blood vessels surrounded by flat endothelial cells in the

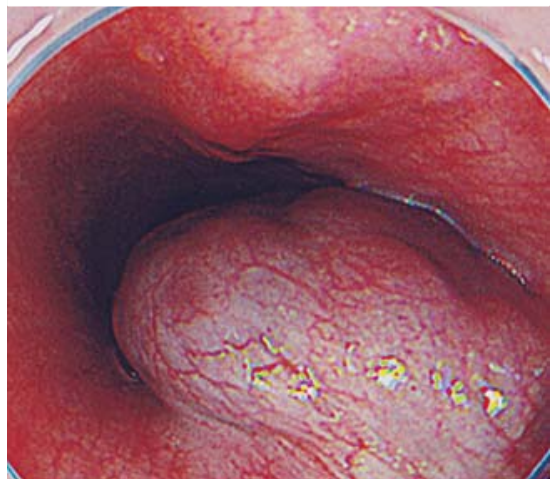

Fig. 1 Endoscopic image showing a flat-based, bluish submucosal mass that was long in the vertical direction in the upper esophagus.

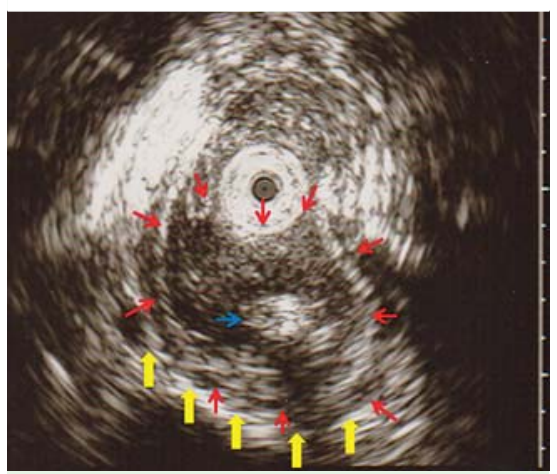

Fig. 2 Endoscopic ultrasound (EUS) image acquired with a 12-MHz probe showing a hypoechoic mass (red arrows) localized to the submucosa (yellow arrows) and a hyperechoic spot within the tumor consistent with calcification (blue arrow).

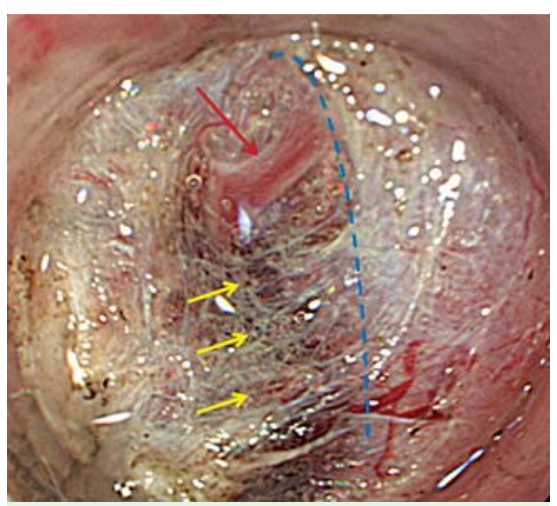

Fig. 3 Image from the endoscopic submucosal dissection (ESD) showing loose connective tissue (yellow arrows) present in the submucosal layer directly above the muscular coat (blue line), which enabled submucosal dissection under direct vision. Hemostasis performed before dissection of the large blood vessels (red arrows) running through the layers prevented intraoperative bleeding.

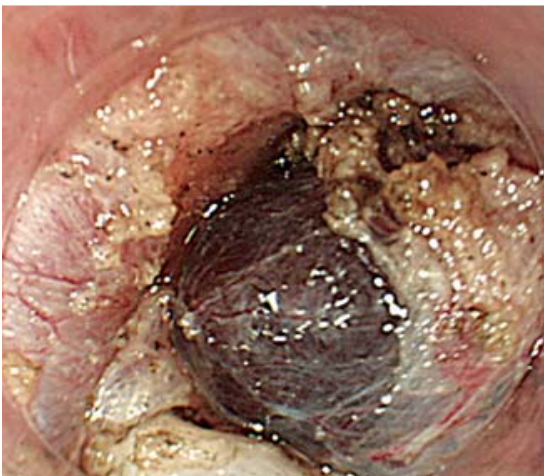

Fig. 4 Image from the endoscopic submucosal dissection (ESD) showing a dark red hemangioma, which required dissection to be performed carefully to avoid damage to it and maintenance of a clear field.

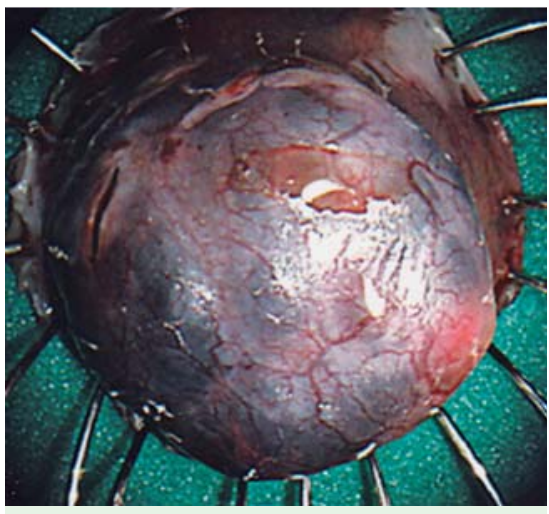

Fig. 5 Macroscopic appearance of the resected specimen, which was $32 \times 30 \mathrm{~mm}$ in size and contained a dark purple, soft mass of $25 \times 23 \mathrm{~mm}$.

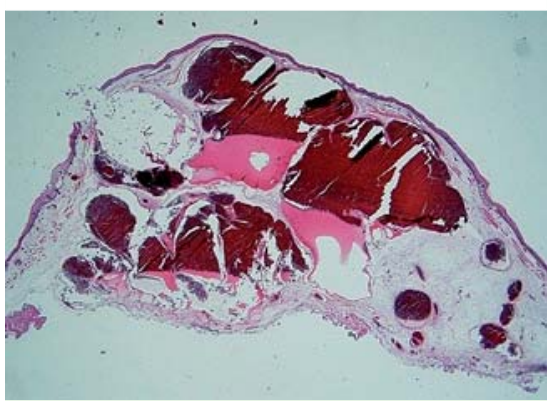

Fig. 6 Histopathological appearance showing outgrowths of dilated blood vessels surrounded by flat endothelial cells in the submucosa, consistent with a diagnosis of cavernous hemangioma. 
submucosa, consistent with a diagnosis of cavernous hemangioma ( $\bullet$ Fig. 6 ).

The patient has now remained free of recurrence for 6 months.

Endoscopy_UCTN_Code_TTT_1AO_2AN

Competing interests: None

H. Kobara, H. Mori, T. Masaki

Department of Gastroenterology and Neurology, Kagawa Medical University School of Medicine, Japan

\section{References}

1 Moersch HJ, Harrington SW. Benign tumor of the esophagus. Ann Otol Rhinol Laryngol 1994; 53: 800-817

2 Cantero D, Yoshida T, Okita K et al. Esophageal hemangioma: Endoscopic diagnosis and treatment. Endoscopy 1994; 26: $250-$ 253

3 Sogabe M, Taniki T, Ito $S$ et al. A patient with esophageal hemangioma treated by endoscopic mucosal resection: a case report and review of literature. J Med Invest 2006; 53: 177-182

4 Uragami T, Kondo K, Kasugai T et al. A case of recurrent esophagealcavernous hemangioma increasing rapidly after surgery. Jpn J Thorac Cardiovasc Surg 1998; 46: $1206-$ 1210

5 Yoshikane H, Suzuki T, Hasegawa $N$ et al. Hemangioma of esophagus: endosonographic imaging and endoscopic resection. Endoscopy 1995; 27: 267-269

\section{Bibliography}

DOI $10.1055 / \mathrm{s}-0030-1256703$

Endoscopy 2012; 44: E134-E135

(c) Georg Thieme Verlag KG Stuttgart · New York . ISSN 0013-726X

\section{Corresponding author}

H. Kobara, MD, PhD

Department of Gastroenterology and Neurology Kagawa Medical University School of Medicine

1750-1 Ikenobe, Miki, Kita

Kagawa 761-0793

Japan

Fax: +81-87-8912158

kobara@med.kagawa-u.ac.jp 